\title{
Teaching Scrum Using Gamification `
}

\author{
Julio C. Guzmán ${ }^{1}{ }^{*}$ and Gustavo López ${ }^{2}$
}

1 Research Center for Communication and Information Technologies (CITIC), University of Costa Rica, San Pedro 11501-2060, Costa Rica

2 School of Computer Science and Computer Science (ECCI), University of Costa Rica, San Pedro 115012060, Costa Rica; gustavo.lopez_h@ucr.ac.cr

* Correspondence: julio.guzman@ucr.ac.cr; Tel.: +506-2511-8016

+ Presented at the 13th International Conference on Ubiquitous Computing and Ambient Intelligence UCAmI 2019, Toledo, Spain, 2-5 December 2019.

Published: 18 November 2019

\begin{abstract}
Teaching Scrum is a complex task in an academic setting. However, it is even more complex when it is taught in an industrial setting. This paper presents our experiences in the implementation of two different Scrum training workshop for workers. We have evaluated and improved these workshops over the past two years. More than 450 trainees with little or no background on Scrum receive the workshop. Furthermore, we present the implementation of three educational devices that automate activities in the context of this workshop. The automation aims to liberate some operative charge from the trainer to allow them to focus on the learning points and explanations of the activities rather than keeping track of the results of the participants.
\end{abstract}

Keywords: Scrum; Agile; eLearning; gamification; Serious Games

\section{Introduction}

Scrum and Agile Methodologies are very popular nowadays. Companies are very interested in adding agility to their processes and teaching their workers to be agile [1]. However, companies used to start training people to become Scrum Master and finish this effort training their teams to achieve "agile teams", without giving enough importance to instilling the concepts and practices related to the Product Owner. That is why we decide to create two workshops in which theory and practice are combined to get a deep understanding of agile principles from the business perspective. We implemented two gamified training workshops, one for Scrum Masters and one for Scrum Product Owners.

These workshops have been imparted 34 times with more than 450 participants. Through the implementation of the workshop, we developed and adapted several activities and games.

One of the main issues of training workers is that they demand more evidence than students in an academic environment. To address this issue, we incorporated technological devices to gather data and improve learning activities during a set of training workshops. This paper presents the results of incorporating sensors, mobile games, and wearables in our Scrum workshop.

The rest of the paper is structured as follows: Section 2 describes the background, including gamification and use of technologies to teach agile or scrum; Section 3 describes the methodology used to create the workshops; Section 4 describes the workshops in detail; Section 5 presents each educational device, and Section 6 concludes the paper showing the results and insights.

\section{Background}

Nowadays, agile knowledge is necessary for project managers, developers, computer science students, and anyone related to the software development process. Agile principles are easy to 
understand but internalize the concepts and apply properly is more complicated. For that reason, trainers used different approaches to teaching Agile. Some of them split the lessons into periods [2]; others used a simulation-based e-learning environment [3]. In the end, all trainers utilize activities in their workshops, based in gamification. The experience report demonstrates the benefits of changing the paradigm of teaching to go deep with each concept [4].

In the agile environment, the use of color papers, post-its, markers, and tape are the standard. After a short search in academic libraries, we found the amplitude activities used for trainers, always using the same material, and a very few use technological tools in the workshops. Usually, the technology is applied in board games simulations [5] with excellent results. In other case report a virtual reality environment that assists students [6] with the goal of supports artifacts needed and achieve communication. The main differences those examples and out workshop consisted of the approached of the use of technology.

\section{Workshops Design}

The workshop design was an iterative process. The final version of the workshop took around a year to be developed. The workshop is designed for groups of 15 trainees. The whole group spend two days, a total of eight hours each day, in the same room. This strategy allows the trainer to generate synergy in the trainees, understand the organization characteristics were the trainees work, and enforce each learning point according to the group needs.

In our case, we first design the activities (aim and learning points) and created an analogical version. Then, we implemented the analogical version in the different iterations of the workshop to evaluate the activities. That allows us the possibility of refinement the teaching method so we could enforce the learning points. In the end, we gamified the lessons and with abundant evidence automate the activity and generated more knowledge in trainees.

A team of experts in agile methodologies collaborates in the design. The first designer is a professional in Computer Science with four years of experience in IT consulting. He holds a CSM, CSPO, and A-CSM certification. The second designer is a researcher with five years of experience in IT consulting. She holds a CSM and CSPO certifications. The third designer is a full-time researcher and Computer Science professor. He holds a CSM, CSPO, and A-CSM certification. He has also seven years of experience as an agile consultor and ten years of experience as a professor. Finally, the fourth designer is a part-time professor Computer Science professor. He is a senior software engineer and holds a CSM certification.

In addition, a group of students in Computer Science participated as assistants in the preparation and execution of the workshop.

\section{Workshops Description}

The two 16-h workshops addressed in this paper were implemented with the experience of 5 trainers that joined efforts to propose the best activities of games to cover each topic [7]. Furthermore, the experiences of the 34 workshop implementations conducted between 2016 and 2019 allowed a natural evolution of many activities. This section describes the topics covered in each workshop and the methodology used to teach them.

The first training workshop is focused on Scrum Fundamentals and Scrum Mastery. This workshop describes the essentials and basic ideas of scrum through exemplification and simulations. Table 1 shows a detailed description of the workshop.

The second training is focused on Product Ownership; this workshop describes product vision and ideation, organizational agility, prioritization, and other essential concepts for product owners. Table 2 details the workshop contents.

Most of the games described in Tables 1 and 2 can be found on the internet. However, the versions used in our workshops implement several adaptations to the workshop context and variations product of our experiences teaching and conducting these activities. 
To decide which activities to automate, we evaluate each training implementation through a survey and one of the questions is, which were the 3 most interesting and fun activities? The results of this survey allowed us to determine which activities were the most appropriate to automate.

Table 1. Scrum Fundamentals and Scrum Master Workshop Design.

\begin{tabular}{lll}
\hline \multicolumn{1}{c}{ Topic } & \multicolumn{1}{c}{ Methodology Description } \\
\hline & Agile Manifesto & Trainer presentation and participant's drawings \\
& Scrum Fundamentals & Ball Game (Scrum Simulation) \\
Day 1 & Scrum Implementation & Trainer presentation and traditional matching \\
& Empiricism & Exemplification \\
& Team communication & Candlewick game \\
& Minimum Viable Product & Exemplification \\
\hline \multirow{2}{*}{ Day 1 Review } & \\
Cynefin & Cynefin Simulation \\
Day 2 & Estimation & Trainer presentation \\
& Context Switching and Multitasking & Games \\
& Release & Penny Game \\
& & Applying what has been learned (game) \\
\hline
\end{tabular}

Table 2. Product Owner Workshop Design.

\begin{tabular}{|c|c|c|}
\hline & Topic & Methodology Description \\
\hline \multirow{7}{*}{ Day 1} & Scrum History & Trainer presentation \\
\hline & Scrum Management Fundamentals & Coin Game and Chair Game (micromanagement) \\
\hline & Organizational Agility & Trainer presentation \\
\hline & Product Ideation & Exemplification and motivational videos \\
\hline & Product Backlog Management & Trainer presentation, vision and backlog exemplification \\
\hline & Prioritization & Prioritization techniques simulation \\
\hline & Product Ownership & Lego Game \\
\hline \multirow{4}{*}{ Day 2} & Release Management & Battleship \\
\hline & Technical Debt & Peanut Game \\
\hline & Minimum Viable Product & Wake up in the morning (game) \\
\hline & Business Value & Business Value Game \\
\hline
\end{tabular}

\section{Educational Devices}

This section describes three educational devices: a sensor, a mobile game and a wearable device that automate the workshop process.

\subsection{Ball Game (Scrum Simulation)}

Ball Game is an activity where trainees have the mission to pass, from hand to hand, as many Styrofoam balls in a timebox of one minute and $30 \mathrm{~s}$. The rules are simple. First, activity is carried out in silence, if a ball falls to the ground, it is not collected and, each ball is passed over the shoulder and received at the height of the hip. Trainees' are who watch over the compliance of the rules. The balls start in a bag, and only a trainee can take balls out of the bag. The trainee that completes the circle is who returns each ball to the bag.

Before starting each iteration, the participants make a projection of the scope. Only those balls that complete the circle will be given as points. At the end of the timebox, we review how much the team managed to do. Next, the group is allowed to speak to perform a retrospective on how to improve the process and makes a new scope projection for the next iteration, taking into account the real speed.

Inside some balls, there is an RFID (Radio Frequency IDentification) sensor to measure the time in seconds that a ball takes to give the circle. From the start until it is considered a valid point. We 
use a PhidgetRFID Read-Write id: 1024_0. First trainee was asked to record the output of each ball and the last trainee to record the income of each ball.

PhidgetRFID was programmed in Python. At the end of each timebox, a record of the time of each RFID was kept or it was indicated if an RFID had gone astray on the way.

At the end of three executions with different groups, the results showed that for a group of 15 trainees, the average time per ball is $26 \mathrm{~s}$ in the first iteration. After the first retrospective, the group manages to reduce the average time to $21 \mathrm{~s}$. In the third iteration, the groups tend to increase the speed and achieve an average time of $16 \mathrm{~s}$. For the last iteration, achieve a stable speed between 18 and $20 \mathrm{~s}$. In the Figure 1, we present evidence of the Ball Game.
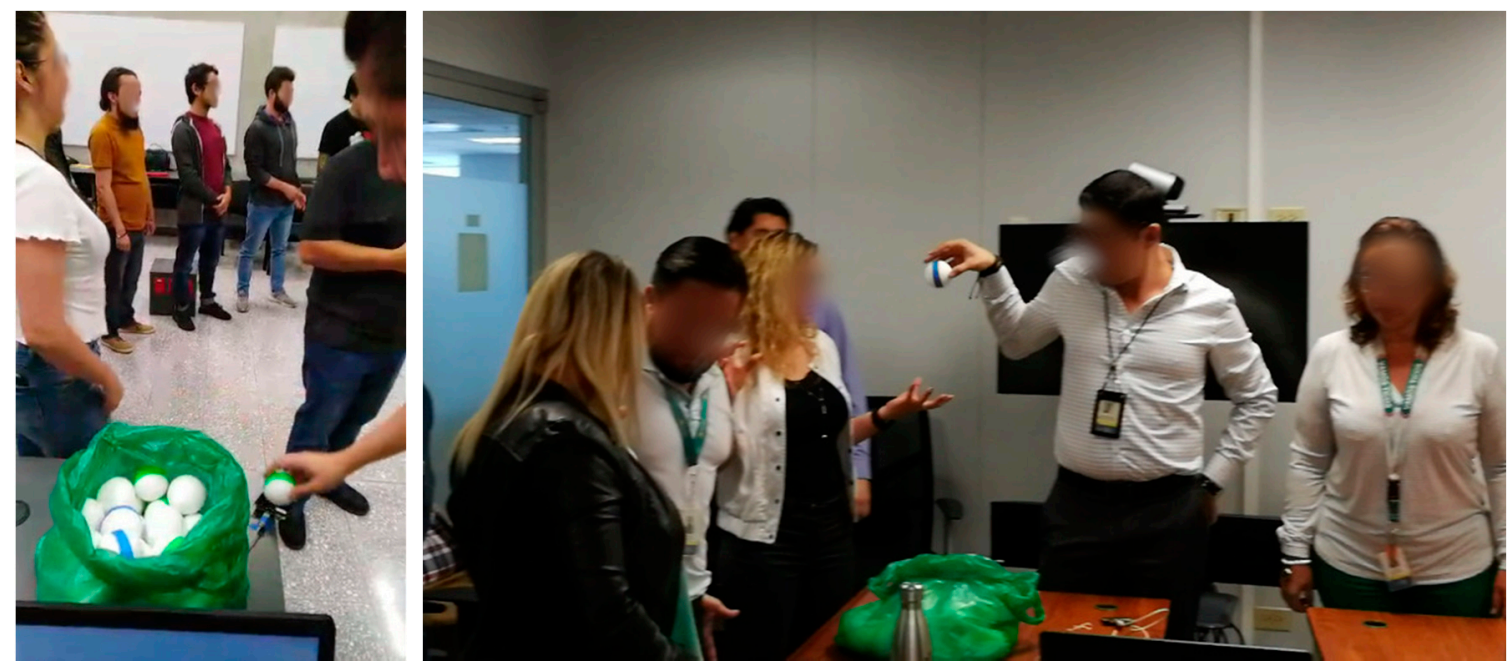

Figure 1. Ball Game (Scrum Simulation) Session.

This activity allowed the trainees to understand concepts such as the commitment of scope in an iteration vs. real scope, mitigation of risks, rapid return on investment, speed in agile, constant deliveries, the value of communication, among others. Besides, the most valuable learning point is the importance of performing retrospectives of the processes in search of continuous improvement.

\subsection{Agile Heads Up}

Agile Heads Up is an implementation of Heads Up! the video game created by The Ellen DeGeneres Show. Figure 2 show the dynamics of the game. Our heads up implementation incorporate a list of core agile concepts taught in the workshop. Some of the concepts include:

- $\quad$ Agile Manifesto

- Scrum Team

- User Story

- Sprint

- Product Backlog

- Burn-down chart

- Definition of Done

- Stakeholder

- Cynefin

- INVEST

- Scope

- Lean

- Inspection

- Adaption

- Transparency
- Empiricism

- Scrum Planning

- Scrum Review

- Daily Scrum

- Scrum Retrospective

- Kanban Board

- Product Vision

- Waterfall

- DevOps

- MVP

- Scrum Master

- Product Owner

- Business Value Canvas

- Pareto's law

- Technical Debt 

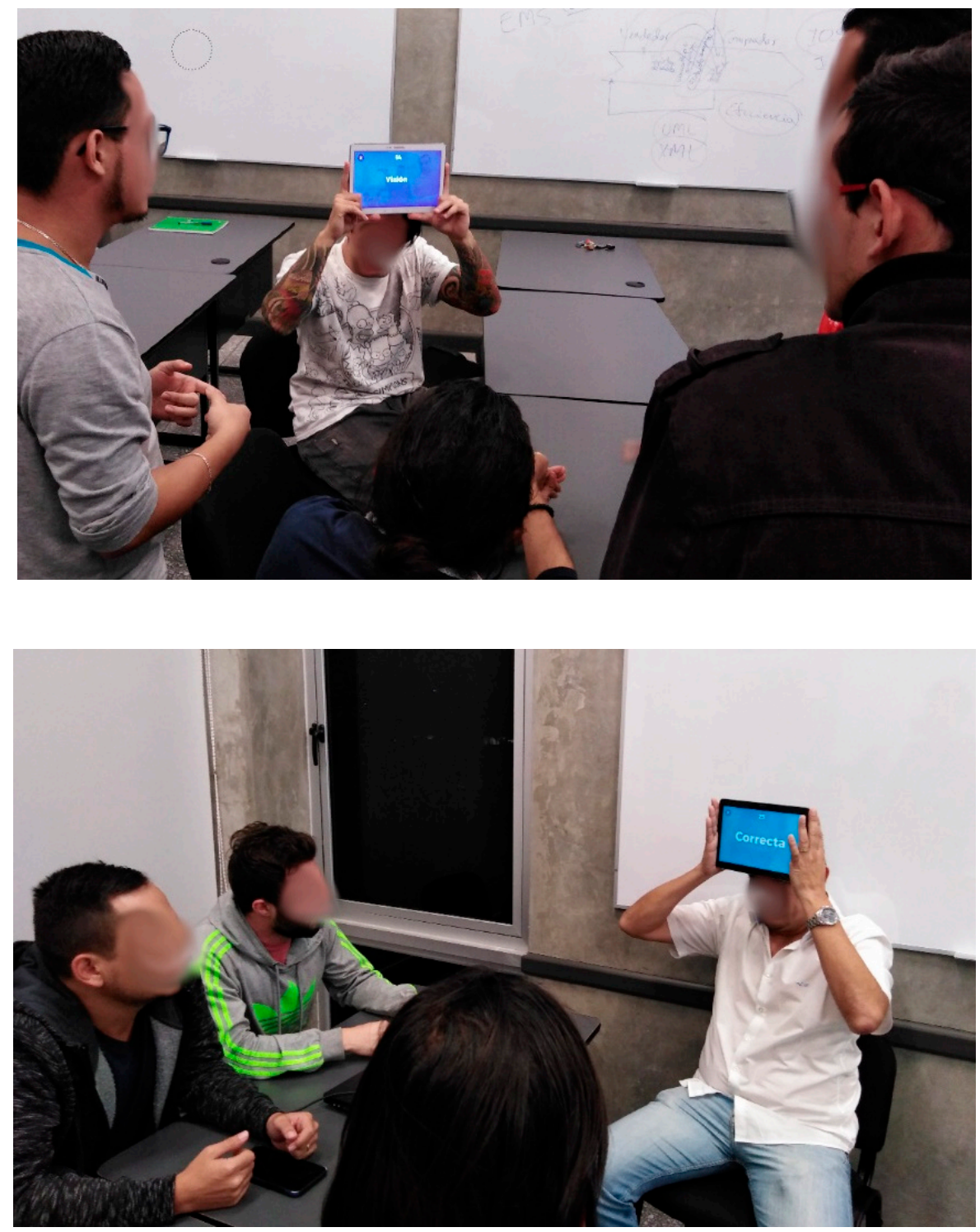

Figure 2. Agile HeadsUp Session.

In the game, a team is asked to describe as many words as possible in a time lapse. The participant holding the tablet must guess the word while the tablet records the rest of the team, providing clues, how can be appreciated in Figure 3. When the participant holding the tablet guesses correctly, they have to tilt the tablet upwards and the application stores the answer as correct, if the participant wants to skip the word, they have to tilt the tablet downwards.

The results of this implementation provide insights on the topics. For instance: participants describing Transparency as: "one of the Scrum Values", Waterfall: "the methodology that was used in the old times" or DevOps as: "when the development team takes care of infrastructure and the servers". This information is useful to determine which topics are clear and which topics require further explanation. 


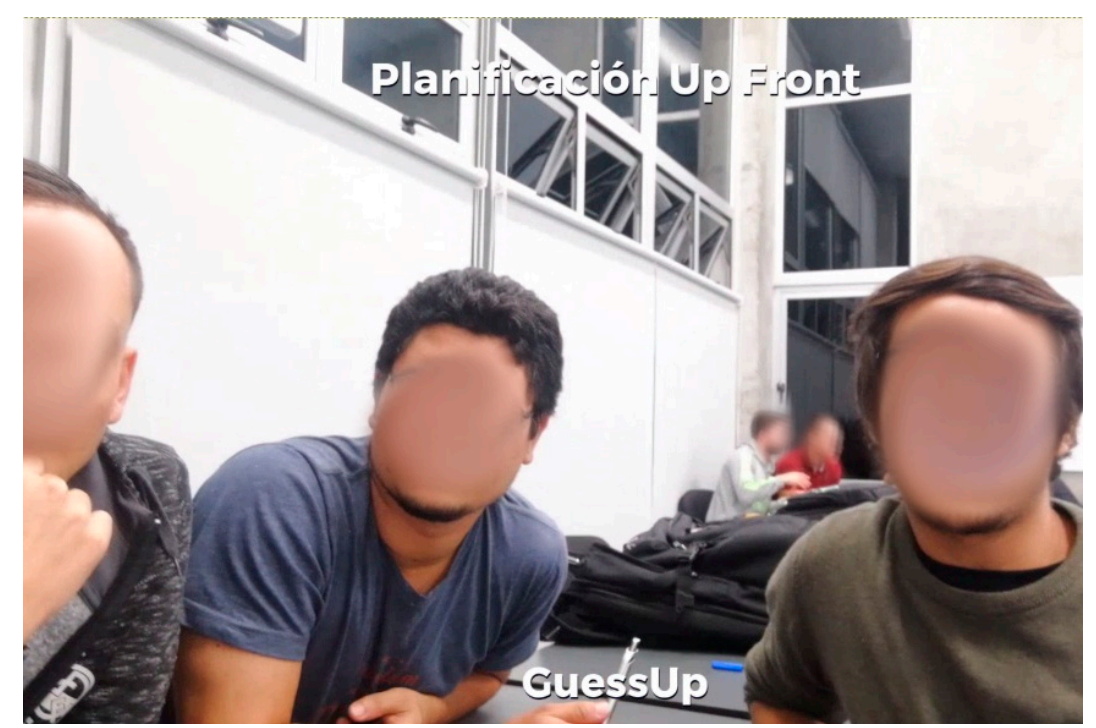

Figure 3. Agile HeadsUp Recording Camera.

The use of this app replaced a quiz that was used to check if participants were able to explain the main concepts addressed in the workshop. Furthermore, it is used to assess each time a new topic is added to either workshop.

To evaluate the heads up we used AttrakDiff. The main results of the evaluation are shown in Figures 4 and 5. The evaluation was conducted by 11 participants in one or the workshops. Results show that the pragmatic and hedonic qualities of the software are good. The only two characteristics that are not well evaluated are: predictability and cheapness. We believe that this is a result of advertisement on the developed app and an error in implementation that sometimes produced an error with the recordings.
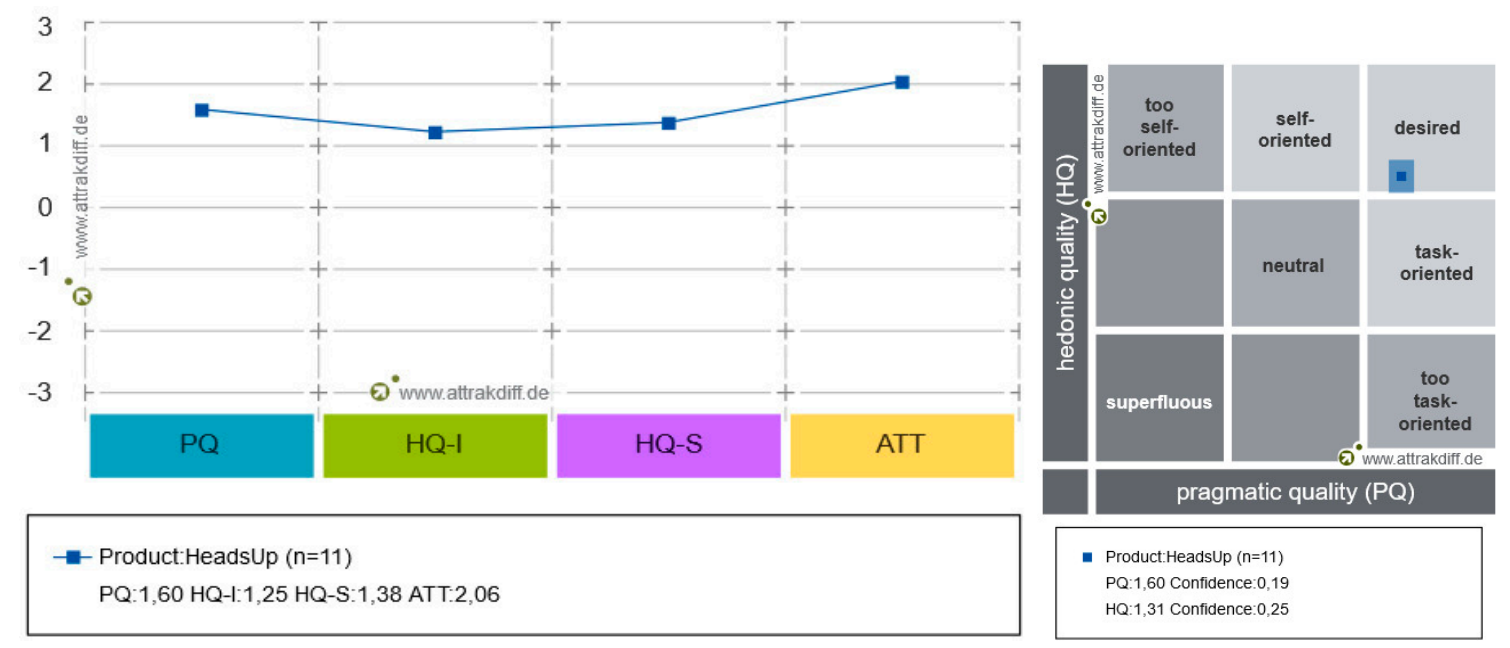

Figure 4. Overall AttrakDiff Results. 


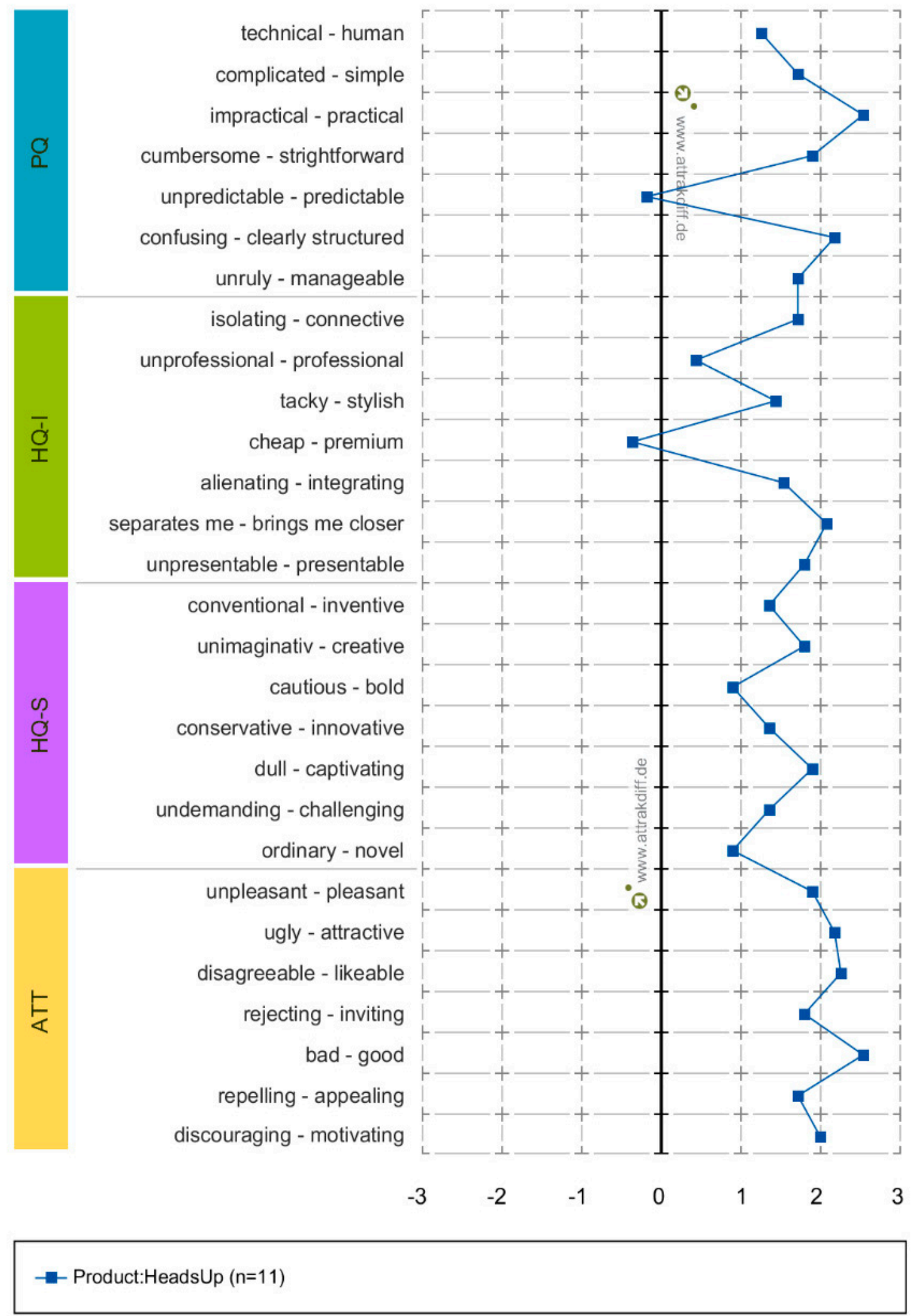

Figure 5. AttrakDiff Results. 


\subsection{Trainer Companion}

Trainer Companion is a smartwatch prototype that aims to guide the trainer in the process of teaching during the workshop. Regularly, technological devices used in workshops seek to reinforce the learning points, but this wearable, instead of being on the side of the trainee is on the side of the trainer. The idea has been validated by two trainers with more than two years of experience teaching workshops.

The smartwatch has a counterpart in a mobile application. There the topics are entered as those of Tables 1 and 2, also to their activities. This order must be done for consistent results. The smartwatch screen shows, which is the current topic and what the next topic is.

When entering the list of topics, it is necessary to indicate not only the name of the topic but also the time estimated by the trainer to teach this topic. The screen of Trainer Companion, a circle of progress is shown as well as the remaining time to move on to the next topic.

Besides, Trainer Companion allows the trainer to make voice notes in case if you want to leave a question waiting for a trainee or reminders. Finally, the Trainer Companion has direct access to the watch's chronometer, this is very useful to have correct time management in the activities. Figure 6 shows the different interfaces of the Trainer Companion.

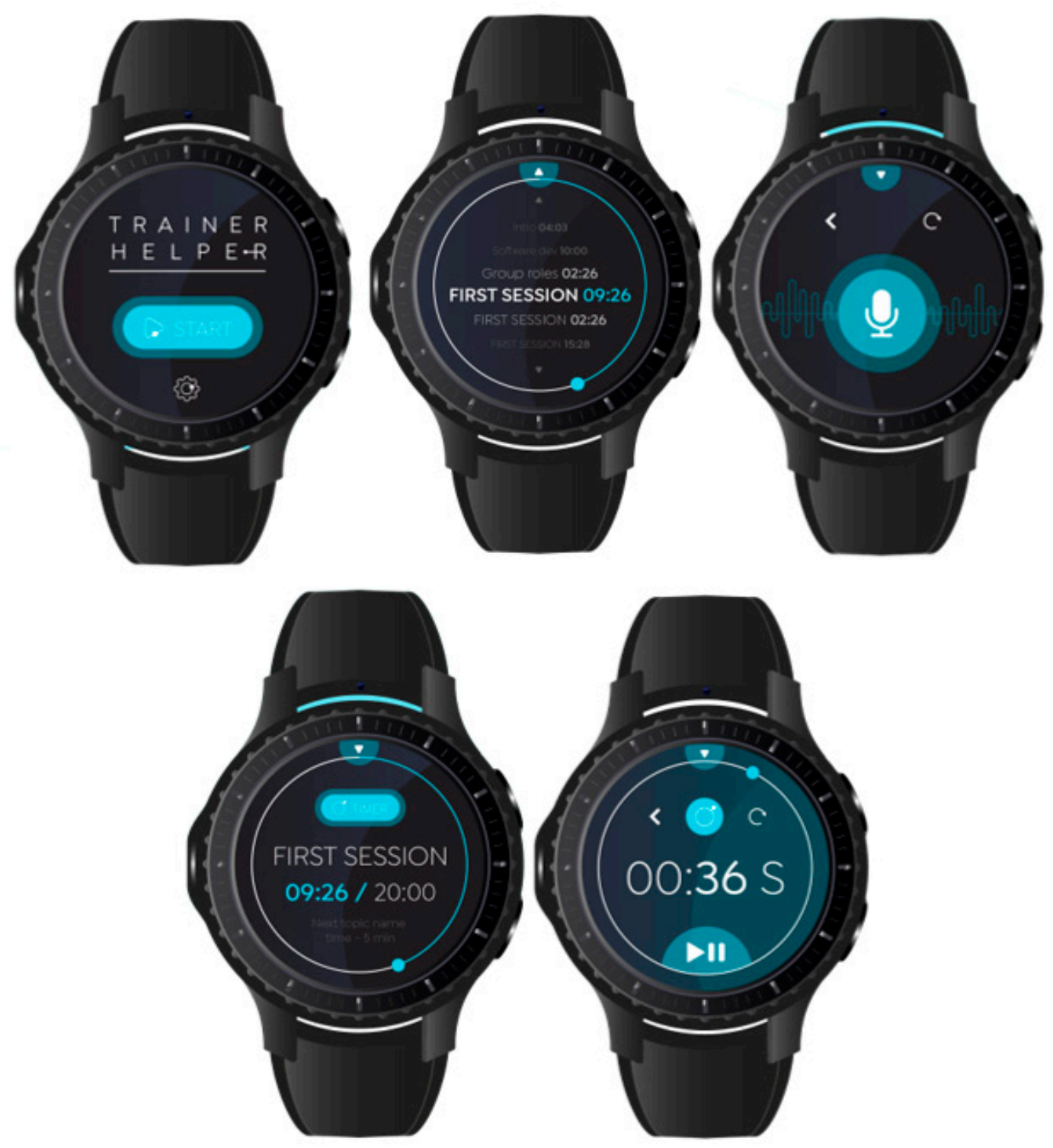

Figure 6. Trainer Companion Interfaces. 
The trainers indicated that the Trainer Companion is ideal to have a correct control of the agenda of the workshop, make a real record of how much time is dedicated to each topic, so they can invest more time in the most important topics and readjust the agenda.

Further, the possibility of having a reminder always visible and at hand what is the current topic, allows the trainer to focus each learning point and make natural transitions between one topic and another. It is expected in future work to carry out an implementation of the Trainer Companion.

\section{Conclusions}

This paper described three educational devices used in Scrum workshops. These educational devices were the result of the automation of well refined educational processes. In this paper, we do not aim to evaluate the implementation of the devices. Mainly because the training has shown to be adequate and the activities are well refined.

The implementation of technological tools is a great benefit to training in three aspects. First, the ball game automation allowed the trainer to gather data in real time of the results of the activity and focus on the learning points instead of counting the number of balls that were dropped or completed the circuit. The use of sensors and simple instruction to the first and last participant were enough to implement this technological tool in the activity.

Second, the agile heads up allowed not only to entertain the participants of the workshop but also to record their ways to express core agile concepts. This information is later used to improve how the concepts are explained and to determine how much each participant learned. The use of mobile devices allowed the replicability of this game, and the recordings are very useful for continuous improvement purposes.

Finally, the trainer companion is a smartwatch app that keeps track of timing and guides the trainer through the workshop. The first approach to this was a paper sheet called the trainer guide. The implementation of this wearable allowed to follow the guide surreptitiously and to track each trainer schedules to assure uniformity between trainers.

The experiences and educational devices described in this paper were excellent assets to improve the workshops and to keep track of participants and trainers. As future work, we believe that the automation of other activities and games could be useful. However, the goal of this automation is not to allow remote training. The goal is to reduce the procedural effort of the trainer to allow them to focus on learning points, explanations, exemplifications, and to provide them with real-time results of the activities that improve the participant's opinions of the workshop.

Author Contributions: Conceptualization, J.C.G. and G.L.; Methodology, G.L.; Software, J.C.G.; Validation, J.C.G. and G.L.; Investigation, J.C.G.; Writing-Original Draft Preparation, J.C.G. and G.L.; Writing-Review \& Editing, J.C.G. and G.L.; Supervision, G.L.; Project Administration, G.L.; Funding Acquisition, G.L.

Acknowledgments: This work was partially supported by the Research Center for Communication and Information Technologies (CITIC) at the University of Costa Rica. Grant No. 834-B4-412.

Conflicts of Interest: The authors declare no conflict of interest.

\section{References}

1 The 11th Annual State of Agile Development Survey. Available online: http://www.agile247.pl/wpcontent/uploads/2017/04/versionone-11th-annual-state-of-agile-report.pdf (accessed on 15 November 2019).

2 Schäfer, U. Training scrum with gamification: Lessons learned after two teaching periods. In Proceedings of 2017 IEEE Global Engineering Education Conference (EDUCON), Athens, Greece, 25-28 April 2017.

3 Zualkernan, I. A., Al Darmaki, H., Shouman, M. A methodology for building simulation-based e-learning environments for Scrum. In Proceedings of 2008 International Conference on Innovations in Information Technology, Al Ain, United Arab Emirates, 16-18 December 2008.

4 Pérez-Castillo, R., Caballero, I., \& Rodríguez, M. Improving the experience of teaching Scrum. In Proceedings of 2018 IEEE Global Engineering Education Conference (EDUCON), Tenerife, Spain, 17-20 April 2018. 
5 de Souza A.D., Seabra R.D., Ribeiro J.M., da Silva Rodrigues L.E. An Experience of Using a Board Serious Virtual Game for Teaching the SCRUM Framework. Available online: https://link.springer.com/chapter/10.1007/978-3-319-77028-4_31 (accessed on 15 November 2019)

6 Rodríguez, G., Soria, A., Campo, M. Teaching Scrum to Software Engineering Students with Virtual Reality Support. Available online: https://link.springer.com/chapter/10.1007/978-3-642-34010-9_14 (accessed on 15 November 2019)

7 Guzmán, J. C., López, G., Aymerich, B. Agile for Newbies: A Scrum Workshop Design and Implementation Process. Available online: https://link.springer.com/chapter/10.1007/978-3-319-93882-0_42 (accessed on 15 November 2019)

(C) 2019 by the authors. Licensee MDPI, Basel, Switzerland. This article is an open access article distributed under the terms and conditions of the Creative Commons Attribution (CC BY) license (http://creativecommons.org/licenses/by/4.0/). 